\title{
Predictors and mediators of sustainable collaboration and implementation in comprehensive school health promotion
}

Citation for published version (APA):

Pucher, K. K., Candel, M. J. J. M., Boot, N. M. W. M., \& de Vries, N. K. (2017). Predictors and mediators of sustainable collaboration and implementation in comprehensive school health promotion. Health Education, 117(1), 2-23. https://doi.org/10.1108/HE-12-2014-0101

Document status and date:

Published: 01/01/2017

DOI:

10.1108/HE-12-2014-0101

Document Version:

Publisher's PDF, also known as Version of record

Document license:

Taverne

Please check the document version of this publication:

- A submitted manuscript is the version of the article upon submission and before peer-review. There can be important differences between the submitted version and the official published version of record.

People interested in the research are advised to contact the author for the final version of the publication, or visit the DOI to the publisher's website.

- The final author version and the galley proof are versions of the publication after peer review.

- The final published version features the final layout of the paper including the volume, issue and page numbers.

Link to publication

\footnotetext{
General rights rights.

- You may freely distribute the URL identifying the publication in the public portal. please follow below link for the End User Agreement:

www.umlib.nl/taverne-license

Take down policy

If you believe that this document breaches copyright please contact us at:

repository@maastrichtuniversity.nl

providing details and we will investigate your claim.
}

Copyright and moral rights for the publications made accessible in the public portal are retained by the authors and/or other copyright owners and it is a condition of accessing publications that users recognise and abide by the legal requirements associated with these

- Users may download and print one copy of any publication from the public portal for the purpose of private study or research.

- You may not further distribute the material or use it for any profit-making activity or commercial gain

If the publication is distributed under the terms of Article $25 \mathrm{fa}$ of the Dutch Copyright Act, indicated by the "Taverne" license above, 
$\mathrm{HE}$

117,1

2

Received 19 December 2014 Revised 4 May 2016 Accepted 6 May 2016

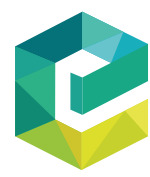

Health Education Vol. 117 No. 1, 2017 pp. 2-23

(C) Emerald Publishing Limited 0965-4283

DOI 10.1108/HE-12-2014-0101

\section{Predictors and mediators of sustainable collaboration and implementation in comprehensive school health promotion}

\author{
Katharina K. Pucher \\ Department of Health Promotion, \\ Maastricht University, Maastricht, The Netherlands and \\ Institute of General Practice and Family Medicine, \\ Witten/Herdecke University, Witten, Germany \\ Math J.J.M. Candel \\ Department of Methodology and Statistics, \\ Maastricht University, Maastricht, The Netherlands \\ Nicole M.W.M. Boot \\ Department of Education and Research, \\ Zuyd Hogeschool, Heerlen, The Netherlands, and \\ Nanne K. de Vries \\ Department of Health Promotion and \\ School for Public Health and Primary Care (CAPHRI), \\ Maastricht University, Maastricht, The Netherlands
}

\begin{abstract}
Purpose - The Diagnosis of Sustainable Collaboration (DISC) model (Leurs et al., 2008) specifies five factors (i.e. project management, change management, context, external factors, and stakeholders' support) which predict whether collaboration becomes strong and stable. The purpose of this paper is to study the dynamics of these factors in a study of multiple partnerships in comprehensive school health promotion (CSHP).

Design/methodology/approach - A Dutch two-year DISC-based intervention to support coordinators of five CSHP partnerships in the systematic development of intersectoral collaboration was studied in a pretestposttest design. To uncover the determinants of sustainable collaboration and implementation of CSHP and to find possible mediators, the authors carried out multi-level path analyses of data on the DISC factors obtained from 90 respondents (response of approached respondents: 57 percent) at pretest and 69 respondents (52 percent) at posttest. Mediation mechanisms were assessed using joint significance tests.

Findings - The five DISC factors were important predictors of implementation of CSHP (explained variance: 26 percent) and sustainable collaboration (explained variance: 21 percent). For both outcomes, stakeholders' support proved to be the most important factor. Regarding sustainable collaboration, mediation analysis showed that stakeholders' support fully mediated the effects of change management, project management, external factors and context. This indicates that the extent of stakeholders' support (e.g. appreciation of goals and high levels of commitment) determines whether collaboration becomes sustainable. The authors also found that the extent of stakeholders' support in turn depends upon a well-functioning project management structure, the employment of change management principles (e.g. creation of a common vision and employment of appropriate change strategies), a favorable organizational context (e.g. positive experience with previous collaboration) and external context (e.g. positive attitudes of financing bodies and supporting health and educational policies). For the actual implementation of CSHP, partial mediation by the support factor was found. There was a direct positive effect of change management indicating that organizational knowledge is also necessary to implement CSHP, and a direct negative effect of project management, probably pointing to the negative effects of too much negotiation in the collaboration.

Research limitations/implications - A design lacking a control group, a small sample and a relatively early assessment after implementation support stopped limit the generalizability of the results.

Practical implications - Strategies targeting the DISC factors can enhance stakeholders' support and thereby promote sustainable intersectoral collaboration and the implementation of CSHP.
\end{abstract}


Originality/value - The DISC model provides a fruitful conceptual framework for the study of predictors and processes in public health partnerships. The importance of stakeholders' support and other factors in the model are demonstrated.

Keywords Health promoting schools, Collaboration, Implementation

Paper type Research paper
Comprehensive school health promotion

\section{Introduction}

Intersectoral collaboration plays an increasingly important role in public health (Barry et al., 2012; Warner and Gould, 2009; Stahl et al., 2006; Butterfoss et al., 1996). Health problems are often multifactorial and can best be solved by combining effective interventions implemented with the support of different sectors. Such multi-strategic approaches to health problems are complex and difficult to implement, however. One of the challenges to their implementation is the establishment of a functional collaboration between stakeholders (Gray, 1989; Zuckerman et al., 1995; Roussos and Fawcett, 2000; Lasker et al., 2001). The ultimate goal is often to develop a stable, long-term and self-supporting collaboration.

Conceptual models of partnership development in public health list factors that are responsible for successful collaboration. These include personal characteristics, attitudes, beliefs and behaviors of relevant stakeholders, the organizational context of the parties involved and the external context of the collaboration (Clark et al., 2006; Feinberg et al., 2004; Florin et al., 2000; Crowley et al., 2000; Kegler and Swan, 2011b). Where previous research paid much attention to the determinants and to the outcomes of intersectoral collaboration, the interactive processes in between these two have been less studied. This particular lack of knowledge has been called the "black box" of collaborative processes (Thomson and Perry, 2006; Wood and Gray, 1991). Lasker et al. (2001) also recognize this knowledge gap and emphasize the need for "the explication of the pathways through which partnership functioning influences partnership effectiveness" (p. 182). They suggest to conceptualize and measure proximal determinants of collaboration outcomes, as well as to identify ways to assess the impact of the proximal determinants on coalition outcomes in order to evaluate coalition functioning. In this respect, especially the work on the Community Coalition Theory (CCAT) is valuable (Butterfoss and Kegler, 2002; Butterfoss, 2007). CCAT has specifically been developed for building community-based partnerships. It has a thorough grounding coming from decades of literature and expertise on coalition building (e.g. Roussos and Fawcett, 2000; Butterfoss et al., 1993). CCAT depicts factors and processes that affect coalition formation, maintenance and institutionalization. The processes by which coalitions achieve their outcomes - thus determine coalition functioning - have recently been studied (e.g. Kegler and Swan, 2011a,b). According to CCAT, the establishment of a diverse stakeholder representation is important in the formation stage. In addition, coalition leadership is required to develop operating procedures and structures, which facilitate member engagement and ensure that benefits for participation outweigh the costs. In the maintenance stage, coalition members need to combine their resources and skills to develop tailored action plans and intervention strategies to solve community problems. These strategies can result in community-level changes (e.g. policy achievement) or community capacities (e.g. new skills), which can then help coalition members to solve new community problems in the future (institutionalization stage). Contextual factors such as politics and local values determine coalitions at every stage.

To study above-mentioned mechanisms, some recent works on CCAT used a quantitative approach, including path analyses (Kegler and Swan, 2011a, b). In the current study, we explored the dynamics within collaborations by using the same quantitative approach. We used the longitudinal data from a multiple-case study on comprehensive school health promotion (CSHP) conducted in the Netherlands between the end of 2008 and 
$\mathrm{HE}$ 117,1

\section{Intersectoral collaboration for CSHP}

CSHP is endorsed by the World Health Organization and has been implemented in different forms worldwide (IUHPE, 2009; Stewart-Brown, 2006; Leurs et al., 2005a). The Dutch equivalent of CSHP, called the Healthy School Approach (HSA), basically includes the following steps: creating a supportive collaboration for the HSA, using demand-driven practices in school health promotion based on the epidemiological data of the school community, prioritizing school needs, compiling a multi-year school health plan, executing the plan, evaluating the activities, and creating an education care continuum by linking available care structures in schools with the necessary structures for prevention. Multi-stakeholder engagement is needed to put the HSA into practice (Buijs, 2005; Leurs et al, 2006; Jongh and Bos, 2010).

Since in the Netherlands schools have no legal obligations to implement health promotion programs and policies, its implementation is stimulated by public health services (PHSs). In the HSA, PHSs function as a linking pin (coordinator) between the education sector, health authorities and public service stakeholders (PSSs). As illustrated in Figure 1, they shape demand-driven practices in school health promotion by matching the available health promotion offer to the health demands of schools. In addition, PHSs fulfill an advisory role to the municipality, to ensure financial and policy support for the HSA. Their activities are based on a legal responsibility for the implementation of local public health policy and youth health care, financed by the municipality (Hirsch Ballin, 2008). Furthermore, at the school level, the implementation of the HSA is professionally assisted by a "health promoting school advisor," who represents different public services and providers (e.g. from the welfare, health, prevention and safety sectors). This can be either a representative from the PHSs or a representative from another public service. The contacts with PSSs are maintained by the

Figure 1.

Collaborative structure in the HSA

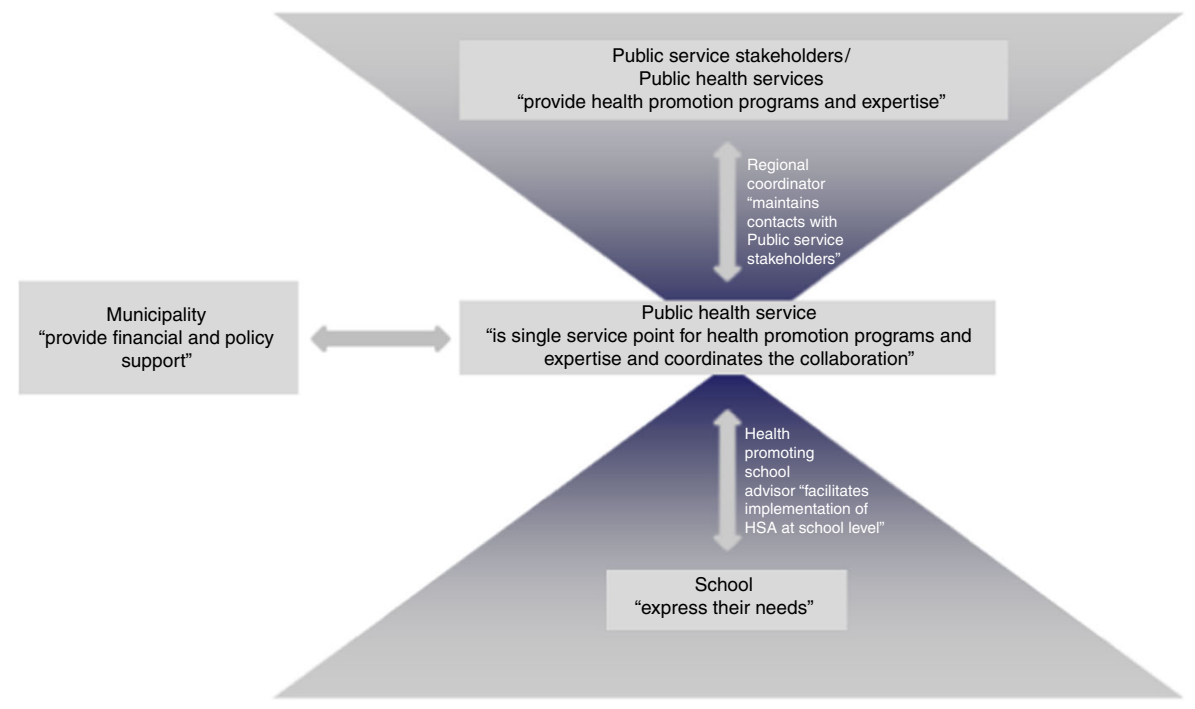


HSA coordinator itself. The organization of the HSA (e.g. task distribution, contacts) can vary between Dutch regions. The organization within the PHS can also vary. Sometimes several departments within the PHS can each fulfill a specific role within the HSA (e.g. the Department of Health Promotion and the Department of Youth Health Care). In those cases, the involvement of these departments in the HSA needs to be considered as well.

For this reason, in this study, intersectoral collaboration is referred to as the joint work of various public services (e.g. PHS, welfare, mental health, youth care) and professionals from different field of expertise within the same organization (e.g. youth health care professionals and health promoters from the PHS).

\section{DISC model}

The first attempt to establish a functional collaboration between these stakeholders was managed by using the practice-oriented DISC model (Leurs et al., 2008). The DISC model originates from Dutch multiple-case studies aimed at bringing different health domains together in integrated care (Van Raak et al., 1999) and is based on organizational change theory (Cummings and Worley, 2001; Daft and Noe, 2001; De Caluwé and Vermaak, 2003). Its validity in the context of the HSA has been established in a single case study (Leurs $e$ t al., 2008) and its application as a diagnostic instrument further confirmed in a study of multiple partnerships (Pucher et al., 2015b). The results of DISC analyses showed to be useful to guide future actions in HSA partnerships. The DISC model includes five factors that predict sustainable collaboration: change management, stakeholders' support, project management, context and external factors. Each factor can be assessed on the basis of a set of subfactors.

The main assumption of the model is that stakeholders' support, which can be assessed at the level of perceptions (i.e. importance, mutual benefits or win-wins), intentions (i.e. intention to trust, to commit and to innovate) and actions (i.e. innovations, investments of resources and personal, and formalization) of the stakeholders involved, determines the progress within the partnership. The collaboration makes progress when stakeholders succeed in translating their positive perceptions into positive intentions and actions. The collaboration stagnates when it fails to enter the action stage. The collaborative process is also affected by factors in the wider context. On the one hand there are contextual factors (i.e. characteristics of organizations, research power and relevant policies) which exert influence on the collaboration and can be influenced by the partners themselves. On the other hand there are external factors (e.g. rules and regulations, financers' attitudes and community notions), which are beyond the control of the collaboration itself. Furthermore, the model assumes that the collaboration varies over phases. During the developmental and initial implementation phase, the collaborative process is dealt with in a project management structure (i.e. who, what, when). This project management structure fades out when the subject of the collaborative process is integrated into regular work of the partner organizations, and the alliance becomes a self-supportive initiative. The transition from incidental, project bound collaboration (i.e. a project with a project-management structure) to joint work embedded in organizational routines (a self-supported collaboration without strict project management but embedded in regular work) is indicated by the shading in Figure 2. This integration in organizational policies is captured in the factors of sustainable collaboration. The process of integration is facilitated by one leader or a small group of leaders enacting the principles of change management (i.e. vision, change perspectives, change strategies and network development).

Finally the model assumes that the subject of the collaboration (i.e. HSA) is further developed under the influence of the partnership. For instance, the HSA is adapted to the characteristics of a region and the stakeholders involved. In other words, there is a clear interdependence between the HSA and the collaboration: when the collaboration is sustained, the implementation of the HSA continues.
Comprehensive school health promotion 
$\mathrm{HE}$ 117,1

6

Figure 2.

The Diagnosis of Sustainable Collaboration (DISC) model

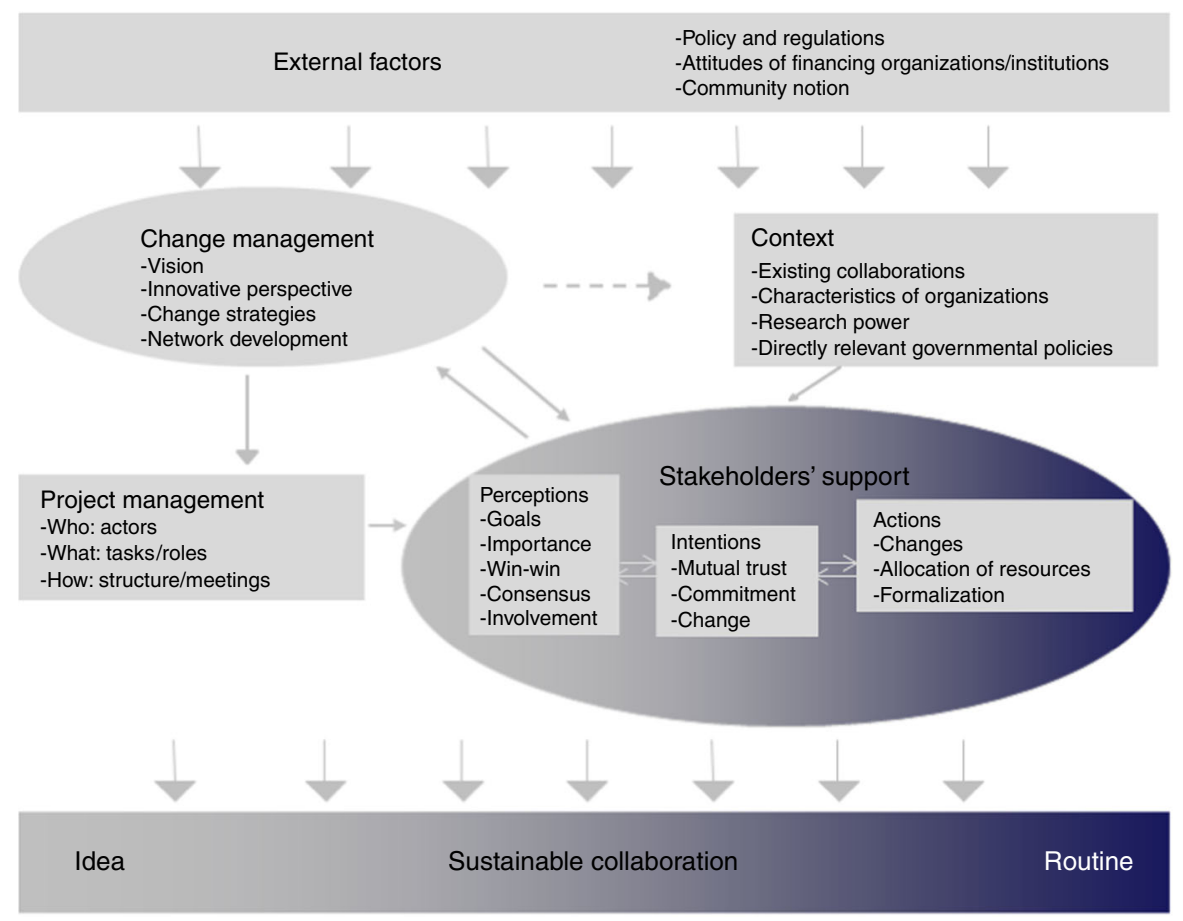

Source: Adapted from Leurs et al. (2008)

Sustainable collaboration, as defined in the DISC model clearly resembles the understanding of this concept as suggested by Steckler and Goodman (1989) and Yin (1979). Those authors emphasize the institutionalization of the subject of collaboration within organizational policies after withdrawal of implementation support, e.g. in terms of funding. Other existing perspectives not included in the DISC conceptualization, feature sustainability as maintenance of health benefits over time (e.g. achieved through partnerships) or view it as capacity-building by relevant actors (e.g. through development of problem-solving capacities that enable the building of relationships and their maintenance) (Shediac-Rizkallah and Bone, 1998). Although it can be assumed that all three can contribute to the sustainability of collaboration, or even that the one can reinforce the effects of the other (Sridharan and Gillespie, 2004), the DISC model in particular focuses on the institutionalization aspect in organizational policies.

The precise relationship between the DISC factors is not yet clear. So far, preliminary data (Leurs et al., 2008; Pucher et al., 2015a) only suggest that the DISC factors of change management, project management, context and external factors can have positive effects on stakeholders' support and that stakeholders' support partially mediates the effects of these factors on sustainable collaboration (Figure 2). However, this mediation has not yet been quantitatively assessed. In addition, previous studies provide some indications for a direct impact of the DISC factors on the implementation of the HSA in schools (Boot et al., 2010; Boot and De Vries, 2012).

\section{Multiple-case study based on the DISC model}

In 2008-2011, the DISC model and results of DISC questionnaires were used to support five Dutch regions in the systematic development of intersectoral collaboration in a 
two-year trajectory. The five HSA collaborations were diagnosed by means of a survey among the relevant stakeholders from health services, PHSs and municipal authorities (Pucher et al., 2015b). Regions independently indicated that adequately situating the HSA within the PHS and positioning it in the region together with PSSs should get priority. Based on the results and the preferences of the regions, recommendations were made to improve the collaboration, followed by a one-year period of support for its implementation. The recommendations targeted representatives of the PSSs and PHSs, and only data from these stakeholders were included in the current study. The DISC recommendations concerned improvements in the management of the collaboration, which were summarized in the following DISC-based strategy: bringing different stakeholders together, developing a common vision, identifying the possibilities and impossibilities for each collaborating partner based on the DISC analysis, determining the desired collaborative structure, developing a task distribution based on the information and discussing the choices at the management and the executive levels. After one year of support, the collaborative process was followed up for an extra year and then ended with an additional assessment of the current state of the collaboration. We present the qualitative data on the managerial activities employed in the regions to bring the DISC-based strategy into practice in a further work (Pucher et al., 2015a).

\section{Research goals}

The longitudinal quantitative data from the DISC survey offered the opportunity to study previous assumptions regarding: the processes connecting DISC factors to the sustainability of the collaboration, including the mediation by stakeholders' support, and the effects of DISC factors on the actual implementation of the HSA in schools. These assumptions are evaluated in the current paper, by using a quantitative approach, involving path analyses.

\section{Methods}

Procedure

Quantitative data on DISC factors were collected in five (of 30) Dutch PHS regions in 2008/2009. Regional coordinators of the HSA in those regions were located at the PHSs and were the central contact persons for this study. To participate in the DISC-based trajectory, PHS regions had to meet several inclusion criteria. Regional coordinators had to indicate that they had sufficient personnel and time to participate in the DISC-based trajectory. They also had to agree to give priority to intersectoral collaboration in their work with the HSA and to start with the DISC-based trajectory by the end of 2008 .

The regional coordinators of the HSA working at PHSs identified relevant stakeholders from the education sector, municipal authorities, PHSs and other PSSs. They announced the topic of research to these persons and distributed materials for the survey (the questionnaire and a brief summary of the HSA). Data collection lasted eight weeks. Reminders were sent after an additional four weeks. The procedure was repeated in 2011 for the posttest measurement.

Table I gives an overview of the partners and the nature of the collaborations.

The coordinators of Regions 1, 2 and 4 indicated that the positioning of the HSA with PSS in the region should get priority in the one year of support. The coordinator of Regions 3 and 5 aimed to position the HSA within the PHS with professionals from different fields of expertise in this period.

\section{Participants}

A total of 158 potential stakeholders at the pretest and 132 potential stakeholders at the posttest were approached by regional coordinators to complete the DISC questionnaire.
Comprehensive school health promotion 

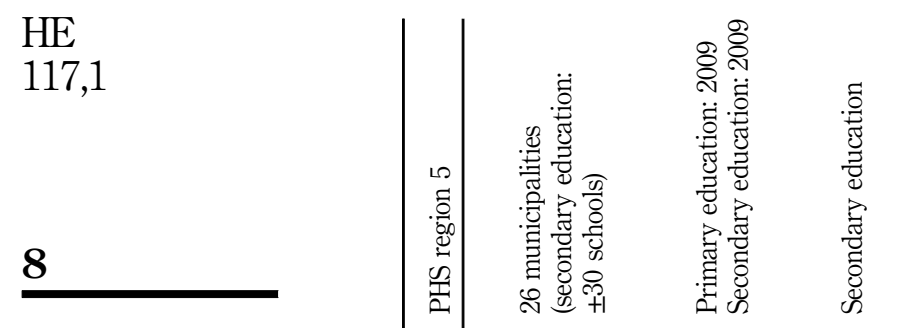

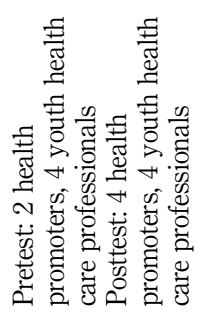

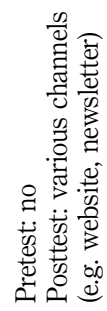

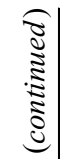

次造 +

迅

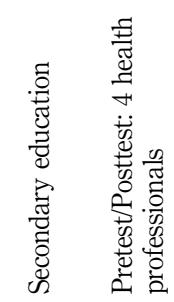

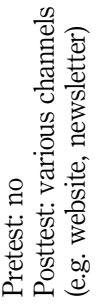

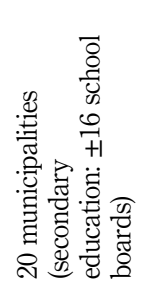

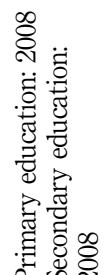

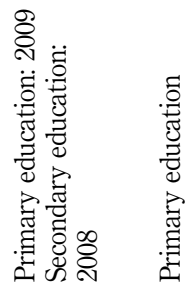

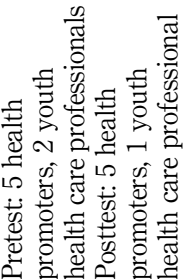

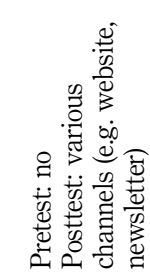

Table I.

Partners and nature of the collaborations
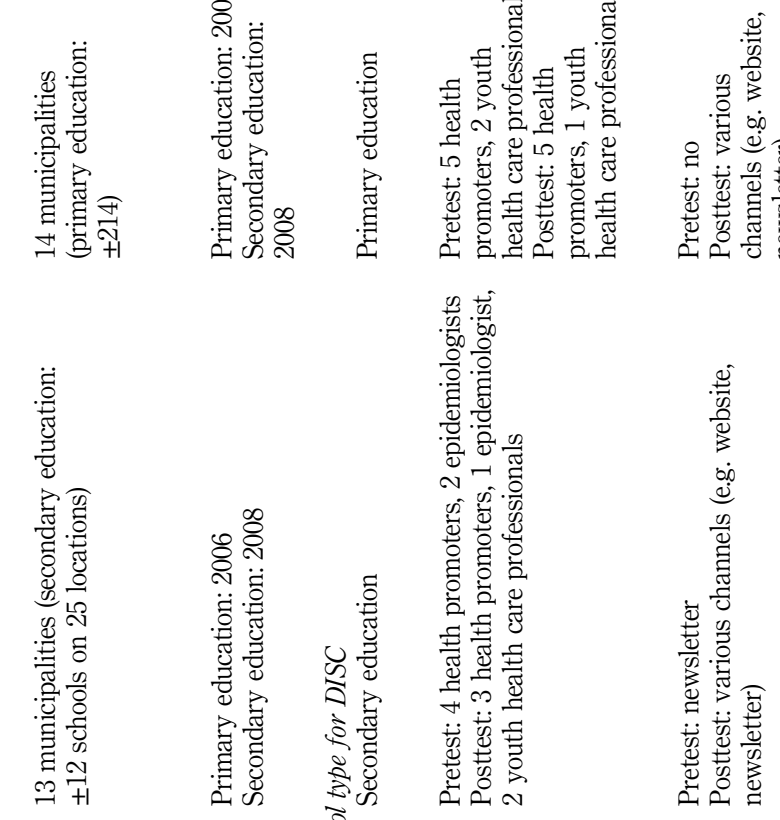


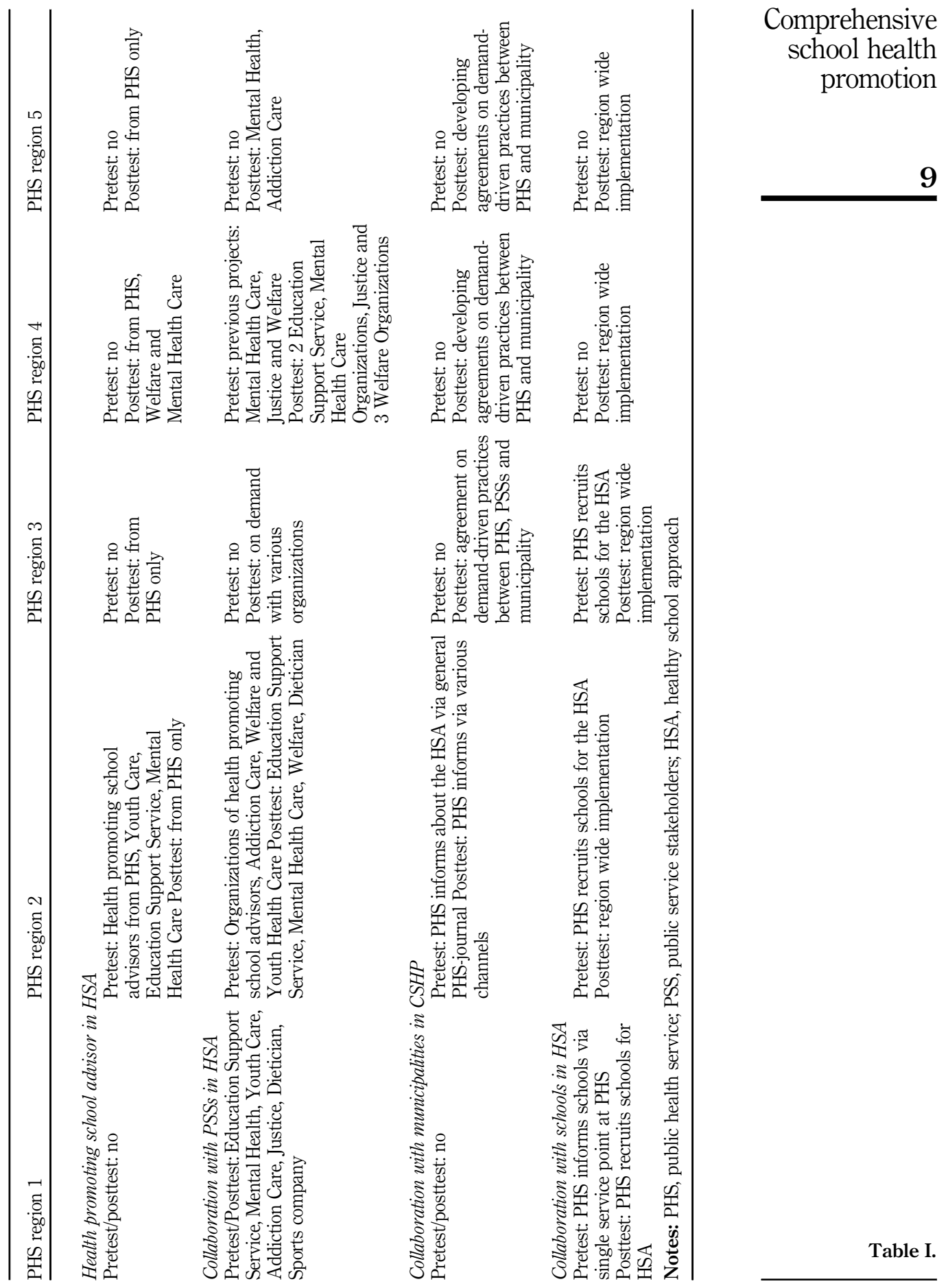


$\mathrm{HE}$ 117,1

The PHS professionals included health promoters, epidemiologists, pediatricians and youth care nurses. PSSs came from the domains of addiction, mental health, social welfare, security and other services like educational support services, dietician centers and sports companies. Coordinators approached more PHS representatives than PSSs. At pretest, 129 PHS representatives and 29 PSSs were approached. At posttest, 108 PHS representatives and 24 PSSs were asked to complete the questionnaire.

\section{DISC questionnaire}

The DISC questionnaire (adapted from Leurs et al. (2008)) relates to 26 subfactors that can be grouped into six DISC factors (change management, project management, context, external factors, stakeholders' support, and sustainable collaboration) with one to five items each, mostly on a five-point scale (completely disagree: 1 to completely agree: 5 ) with the additional option "don't know." Stakeholders' support is measured at the level of stakeholders' perceptions, intentions and actions. Examples of the items used in the questionnaire to assess stakeholders' perceptions asked whether they appreciated the goals of the HSA ("I think demand-driven practices in school health promotion are important for the educational sector") and whether they thought that working together for the HSA was of interest for their own organization ("I think it is important that my organizations participates in the HSA"). Example items to assess stakeholders' intentions related to the subfactors of willingness to trust ("I think that the HSA partners can be trusted") and willingness to commit ("I think that the development of the HSA is the task of my organization"). Stakeholders' actions were assessed by items such as "My organization implemented changes for the HSA" (belonging to the subfactor changes) and "My organization invests in the HSA though allocation of personnel" (belonging to the subfactor resources). Example items for the factor of change management are "The HSA goals are clear" (subfactor vision) and "The HSA is accepted because of good PR" (subfactor change strategies). To assess project management items were used like "There is a clear task distribution" (subfactor task distribution) and "There is a clear communication structure" (subfactor communication). The context of the HSA was assessed by items like "My organization is open to innovations" (subfactor organizational characteristics) and "My organizations can influence health policy" (subfactor relevant policies). Example items to measure external factors were "The HSA fits into the health policy"(subfactor policies and regulations) and "The most important financer appreciates the idea of the HSA" (subfactor attitude of most important financier).

The main outcome measure of our study was the DISC factor of sustainable collaboration, which was assessed with six contrasts evaluating the extent of institutionalization of CSHP and the collaboration: project-bound (i.e. a project with a project-management structure) vs regular work (i.e. a self-supported collaboration without strict project management but embedded in normal routines), network support vs individual actions, research vs practical, systematic vs ad hoc, practical vs theoretical, single service point at PHS for health promotion programs for schools (i.e. the linking-pin function of the PHSs described earlier) vs fragmented health promotion programs for schools (i.e. uncoordinated overload of schools with school-based programs). Collaboration members were asked to indicate for each contrast, on a five-point scale "How do you characterize the HSA in your region?" The contrast "project-bound vs regular work" refers to the transition indicated by the shading in Figure 2. The contrast "single service point at PHS for health promotion programs for schools vs fragmented health promotion programs for schools" refers to the linking pin function of PHSs between the education sector, health authorities and health services (Figure 1). At the PHSs, health promotion programs from different health services are collected and provided to schools tailored to the school health needs. Such demand-driven practice aims to reduce 
fragmentation in school health promotion. A description of the all DISC factors is provided in Table AI.

A second important outcome measure was the degree to which HSA was implemented in schools. This construct was assessed by measuring the execution of the different HSA activities: creating stakeholders' support, assessing the school health situation, prioritizing school needs, compiling a school health plan, executing the plan, evaluating health promotion activities and linking available infrastructure for care at schools with prevention. The specific instruction for coalition partners was to indicate on a three-point scale (1: no, 2: somewhat, 3: yes) whether their own organization performed these activities. The last activity "linking available infrastructure for care in schools with prevention" is specific to the organizational structure for school health in the Netherlands (Leurs et al., 2005b).

\section{Statistical analyses}

The scores for specific subfactors of each DISC factor were combined into a mean score. The same was done with the scores on items measuring the HSA activities. The DISC subfactors and items for HSA activities were considered formative indicators and satisfied the criteria proposed by Diamantopoulos and Winklhofer (2001) for averaging the scores on such indicators.

The determinants of stakeholders' support, sustainable collaboration and implementation of HSA activities were examined using path analyses. The relations between pretest-posttest difference scores as obtained for each of the stakeholders for the several DISC factors were analyzed. As a specific example, when examining whether change management was a determinant of sustainable collaboration, changes in sustainable collaboration between pre and post measurement were related to changes in change management. This was done in a multi-level analysis, where time points were considered to be nested within stakeholders and stakeholders were nested within collaborations, and in addition to measurements on change management at pre and posttest, a time factor (indicating pre vs posttest) and measurements on other DISC factors at pre and posttest (such as project management, context) were included as predictors. Including these predictors, allowed for correcting the influence of change management on sustainable collaboration for a set of possibly confounding covariates. The effect of the time factor was considered to reflect the effect of the DISC-based trajectory.

The multi-level analysis was performed through linear mixed regression modeling involving a random intercept that varied across both collaborations and, within collaborations, across stakeholders. This allowed to control for dependencies between stakeholders' measurements within the same collaboration as well as for dependencies in stakeholders' measurements across time. This also allowed for the inclusion into the analyses both of respondents with complete data and also those who participated only in the pretest or posttest. Compared to an analysis based on complete cases only (that participated in both pretest and posttest), the present procedure enabled a more reliable estimation and test of the effects of the determinants of sustainable collaboration and executed HSA activities as well as associated mediation mechanisms.

The intraclass correlations which reflected the dependencies between stakeholders' answers within the same collaboration turned out to clearly exceed 0.00 up to 0.53 (see Tables AII and AIII), thus supporting the inclusion of a third level into the mixed regression analysis, next to the level of stakeholders and measurement times.

Joint significance tests, as described by Preacher and Hayes (2004) and MacKinnon et al. (2002), were used to assess possible mediation effects of stakeholders' support in these pathways. Stakeholders' support was a full mediator when: it was significantly predicted by a DISC factor; it significantly predicted sustainable collaboration; and sustainable collaboration was not significantly predicted directly by a DISC factor. When the third
Comprehensive school health promotion 
$\mathrm{HE}$ 117,1

Table II.

Response DISC questionnaire and included number of respondents in analyses condition was not satisfied, we concluded that stakeholders' support partially mediated the effect of the DISC factor.

Cohen's $d$ effect sizes (ES) were calculated for significant relationships between binary and continuous variables and were interpreted based on Cohen's (1992) categorization, in which $\mathrm{ES}=0.20,0.50$ and 0.80 represent small, medium and large effects, respectively. Cohen's $f^{2}$ ES were calculated for significant relationships between continuous variables and were also interpreted based on Cohen's (1988) categorization, in which ES $=0.02,0.15$ and 0.35 represent small, medium and large effects, respectively.

Finally, the power of the DISC model to predict sustainable collaboration and the execution of the HSA activities was calculated based on the amount of explained variance in these outcome measures (Snijders and Bosker, 1999).

Statistical analyses were conducted using SPSS 20.

\section{Results}

Response

Of the 158 stakeholders who were approached for the pretest and the 132 approached for the posttest, 90 (57 percent) and 69 (52 percent), respectively were able to be included in the analyses (Table II). Drop-out was due to changes in organizational tasks of collaborating parties in response to organizational developments (i.e. mergers, reorganizations, government cutbacks) and changing policies, but also to the more specific collaborative goals, as collaboration progressed, leading to a poorer fit between the agendas of some organizations and the collaborative agenda.

\section{Which collaborative processes predict sustainable collaboration?}

Path analyses for the outcome measure sustainable collaboration (Figure 3) show that stakeholders' support is the strongest predictor of this measure $(\mathrm{ES}=0.08)$. Change management, project management, context and external factors were not directly associated with sustainable collaboration. Instead, the joint significance tests suggest that the changes over time on change management, project management, contextual and external factors

\begin{tabular}{|c|c|c|c|c|c|c|}
\hline & PHS region 1 & PHS region 2 & PHS region 3 & PHS region 4 & PHS region 5 & Total \\
\hline \multicolumn{7}{|c|}{ Pretest } \\
\hline & PHS: 5/5 & PHS: 9/9 & $\begin{array}{l}\text { PHS: } 25 / 32 \\
\text { Per department } \\
\text { YHC: } 12 / 14 \\
\text { HP: } 11 / 16 \\
\text { Others: } 2 / 2\end{array}$ & PHS: 11/19 & $\begin{array}{l}\text { PHS: } 20 / 64 \\
\text { Per department } \\
\text { YHC: } 12 / 44 \\
\text { HP: } 8 / 18 \\
\text { Others:0/2 }\end{array}$ & PHS: 70/129 (54\%) \\
\hline & PSS: 5/7 & PSS: 5/6 & PSS & PSS: 10/16 & PS & PSS: 20/29 (69\%) \\
\hline Total & $10 / 12$ & $14 / 15$ & $25 / 32$ & $21 / 35$ & $20 / 64$ & $90 / 158(57 \%)$ \\
\hline \multicolumn{7}{|c|}{ Posttest } \\
\hline & PHS: $6 / 9$ & PHS: 7/7 & $\begin{array}{l}\text { PHS: } 20 / 36 \\
\text { Per department } \\
\text { YHC: } 8 / 18 \\
\text { HP: } 11 / 17 \\
\text { Others: } 1 / 1\end{array}$ & PHS: 8/8 & $\begin{array}{l}\text { PHS: } 10 / 48 \\
\text { Per department } \\
\text { YHC: } 4 / 34 \\
\text { HP: } 5 / 12 \\
\text { Others: } 0 / 2 \\
\text { Unknown: } 1\end{array}$ & PHS: 51/108 (47\%) \\
\hline Total & $\begin{array}{l}\text { PSS: } 5 / 7 \\
11 / 16\end{array}$ & $\begin{array}{l}\text { PSS: } 3 / 3 \\
10 / 10\end{array}$ & $\begin{array}{l}\text { PSS: - } \\
20 / 36\end{array}$ & $\begin{array}{l}\text { PSS: 9/12 } \\
17 / 20\end{array}$ & $\begin{array}{l}\text { PSS: } 1 / 2 \\
11 / 50\end{array}$ & $\begin{array}{l}\text { PSS: } 18 / 24(75 \%) \\
69 / 132(52 \%)\end{array}$ \\
\hline
\end{tabular}

Notes: PHS, public health service; PSS, public service stakeholders; YHC, youth health care; HP, health promotion; others, professionals from work and health and communication departments 


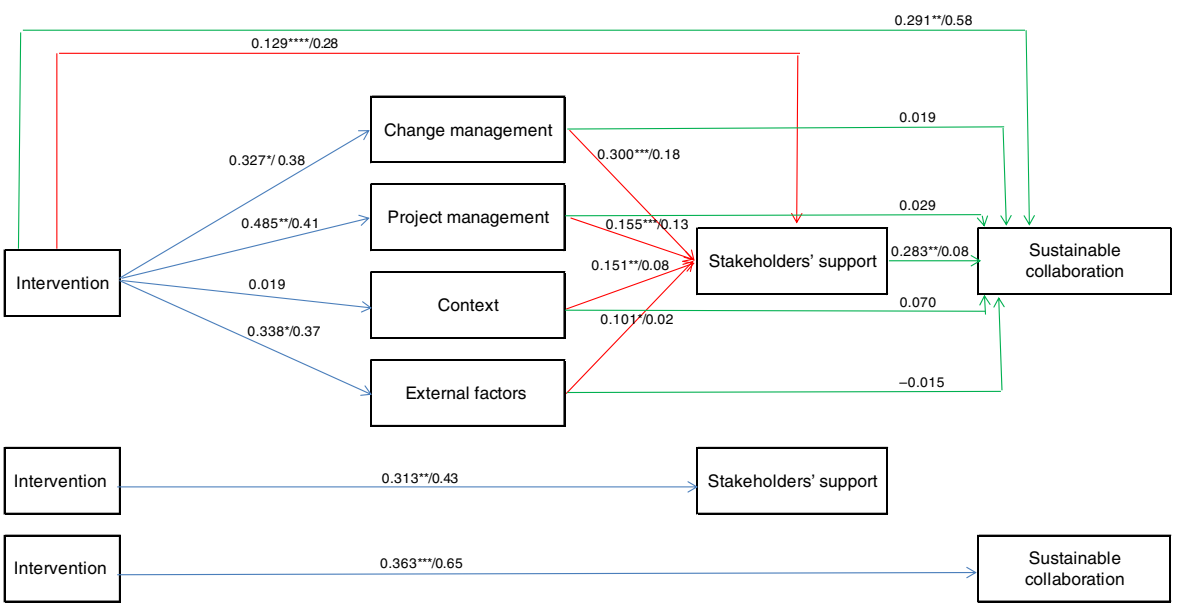

Notes: Numbers reported at the arrows are: regression coefficient (difference score at pretest compared with posttest)/effect size. ${ }^{*} p<0.05 ;{ }^{* *} p<0.01 ;{ }^{* *} p<0.001 ;{ }^{* * * *} p<0.10$

were fully mediated by stakeholders' support, with change management having the largest association with on stakeholders' support $(\mathrm{ES}=0.18)$ and the other DISC factors having smaller associations $(\mathrm{ES}=0.02-0.13)$. The amount of variance of sustainable collaboration explained by the DISC factors was 21 percent.

\section{Which collaborative processes predict the implementation of the HSA?}

The importance of the stakeholders' support was also found for the implementation of HSA. Stakeholders' support was the strongest predictor of the implementation of the HSA $(\mathrm{ES}=0.10$; Figure 4). However, different from the outcome of sustainable collaboration, stakeholders' support only partially mediated the associations between the DISC factors and the execution of the HSA. Change management and project management were directly

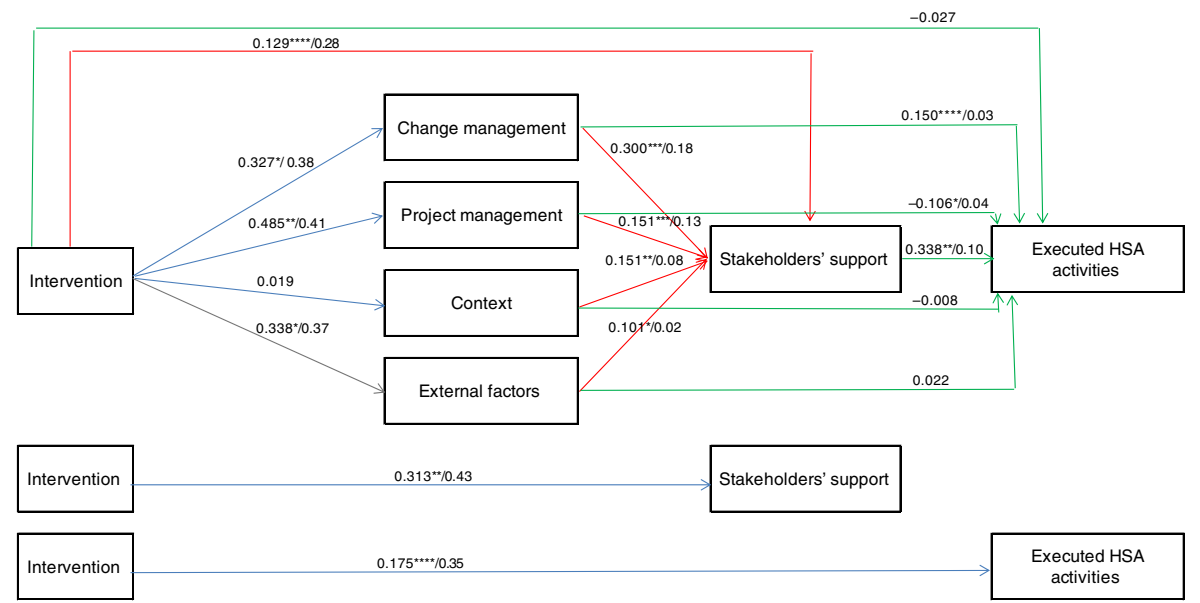

Notes: Numbers reported at the arrows are: regression coefficient (difference score at pretest compared with posttest) effect size. ${ }^{*} p<0.05 ;{ }^{* *} p<0.01 ;{ }^{* *} p<0.001 ; * * * * p<0.10$
Comprehensive school health promotion

Figure 3.

Path-analysis for sustainable collaboration based on difference scores between pre and posttest
Figure 4. Path-analysis for executed HSA activities based on difference scores between pre and posttest 
$\mathrm{HE}$ 117,1

associated with the implementation of the HSA, too: change management had a medium positive direct association $(\mathrm{ES}=0.18)$ with the execution of the HSA activities, whereas project management had a small negative association $(\mathrm{ES}=0.04)$ on their implementation. The DISC factors explained 26.3 percent of the implementation of the HSA.

Further exploration of the DISC factor project management, which includes the subfactors awareness of actors, clear task distribution and communication, showed that the communication subfactor was directly and negatively associated with the execution of the HSA activities $(-0.09, p<0.10 ; \mathrm{ES}=0.02)$. Our analysis to find out which of the seven HSA activities was negatively associated with communication showed a direct negative association of communication and execution of health promotion activities $(-0.16, p<0.05$; $\mathrm{ES}=0.02)$.

\section{What are the effects of the DISC-based trajectory on the DISC factors and both outcome measures?}

The DISC-based trajectory was positively associated with all DISC factors except for the context factor, of which the score did not change over time. The largest changes over time were found on project management $(\mathrm{ES}=0.41)$ and change management $(\mathrm{ES}=0.38)$ and external factors $(\mathrm{ES}=0.37$ ), followed by changes on stakeholders' support $(\mathrm{ES}=0.47$; see Figures 3 and 4).

The joint significance test suggests that the association between the DISC-based trajectory and stakeholders' support was fully mediated by the other DISC factors, with change management being the strongest predictor of stakeholders' support $(\mathrm{ES}=0.18)$, though the association between the trajectory and stakeholders' support was close to significance $(p=0.058)$.

When the DISC factors were not considered as covariates in the analyses, results showed that the overall associations between the DISC-based trajectory and stakeholders' support $(\mathrm{ES}=0.43)$ was of small size and between the trajectory and sustainable collaboration $(\mathrm{ES}=0.65)$ was of medium size. The associations between the trajectory and the implementation of the HSA activities $(\mathrm{ES}=0.35)$ was small and almost reached significance $(p<0.10)$.

\section{Discussion}

This study attempted to open up the "black box" of collaborative processes by which sustainable collaboration evolves and CSHP is implemented, using mediation analyses based on the DISC model. It used longitudinal data from the two-year DISC-based trajectory, which targeted the systematic development of intersectoral collaboration in CSHP. The systematic approach included the assessment of facilitating and hindering conditions for collaboration which set the basis for strategic planning. Targets to be accomplished were better change management and project management (DISC-based strategy) to enhance stakeholders' support. Professional support was delivered to attain these targets. In the following, we discuss the most important findings and compare these findings with the results of inquiries evaluating health promotion in schools or studying collaboration in public health.

Our results show the relevance of the DISC factors (change management, project management, external factors context, and stakeholders' support) for predicting both the outcome measures, namely, the sustainability of collaboration and the implementation of HSA activities. Stakeholders' support proved the most important. In addition, the results of the joint significance analyses showed that the associations between the DISC factors and both outcomes were to a large extent mediated by the support factor. These findings demonstrate on the one hand the necessity of stakeholders' support to integrate joint implementation of the HSA into organization policies of relevant parties. On the other hand, these results indicate that a well-functioning collaboration, using change management 
principles and having a favorable organizational (e.g. openness to innovations and positive experience with previous collaborations) and external context (e.g. positive attitudes of financing bodies and supporting health and educational policies) can positively influence this support. These results are consistent with the relationship between the DISC constructs suggested by Leurs et al. (2008) and support the conclusions of other scholars in this area (Boot et al., 2010; Deschesnes et al., 2010) and other fields (Mur-Veeman and Van Raak, 1994; Van Raak et al., 2003). For example, Boot et al. (2010) and Deschesnes et al. (2010) reported that consensual understanding concerning the CSHP goals and the way to disseminate a comprehensive approach to schools has to be developed, between the health sector and the educational sector, to implement CSHP (both, goals and consensus, are subfactors of the stakeholders' support factor). Leurs et al. (2008) also found that competitive feelings (i.e. lack of trust within the stakeholders' support factor) between the stakeholders from different sectors were destructive for sustainability of the collaboration. Others showed that the levels of commitment among stakeholders can be influenced by partnership managers when they cleverly adapt to the stakeholders' circumstances, requiring skillful communication and knowledge about the goals, interest and circumstances of coalition partners (Mur-Veeman and Van Raak, 1994; Van Raak et al., 2003). In the DISC-based trajectory, regional coordinators enhanced stakeholders' support by change management targeting the establishment of a common vision, consensual commitment about the HSA concept, and project management tailored to the possibilities of involved organizations. A detailed description of the specific management activities can be found elsewhere (Pucher et al., 2015a).

Further, our study showed that there was a direct link between change management and the implementation of the HSA, showing that employing change management principles (e.g. creating a common vision and employing change strategies to enhance trust, consensus and commitment) had a direct positive influence on the implementation of the HSA. Knowledge and competencies relating to change management are probably necessary to develop and implement the HSA in schools (Boot et al., 2010; Boot and De Vries, 2012; Deschesnes et al., 2013; Teutsch et al., 2014; Flaschberger et al., 2013). Previous studies showed that a lack of professional knowledge to promote change in schools (Boot et al., 2010; Teutsch et al., 2014) and to create leadership in the school community (Boot and De Vries, 2012), as well as a limited ability to translate knowledge into innovative practices (Deschesnes et al., 2013; Flaschberger et al., 2013) form important barriers to the implementation of comprehensive approaches in schools. It is conceivable that the knowledge and skills that coordinators acquired to improve the collaboration during the DISC-based trajectory were also used for the implementation of the HSA at school level.

Nevertheless, despite the positive associations with stakeholders' support and change management, the improvements in the implementation of the HSA at the end of the trajectory were only small and only close to significance. It might be that change management, which basically included negotiation to create a common vision and to gain consensus and commitment (Pucher et al., 2015a), was effective as regards establishing stakeholders' support for the HSA activities, but less effective in terms of getting things done. In fact, our results suggest that ongoing negotiations could have slowed down the implementation of the HSA in schools, since communication (a subfactor of project management) had a negative effect on the implementation of the HSA. Probably final decisions on particular issues were difficult to make due to the context of organizations involved. Collaborating organizations were going through mergers, reorganizations, were affected by the financial crisis and were searching for a new position on the market, which did not allow them to enter into final and long-term agreements about their contributions. In addition, collaborations entered a new public health policy cycle, which caused additional workload. "Collaborative inertia," which refers to the lack of progress or small successes
Comprehensive school health promotion 
$\mathrm{HE}$ 117,1

which require a lot effort, has also been observed in other collaborations (Huxham and Vangen, 1996, 2000; Vangen and Huxham, 2003). One possible explanation for collaborative inertia that has been suggested is the desire to obtain full commitment from stakeholders, which can result in endless negotiation. Collaborative advantage (the opposite of collaborative inertia) on the other hand has been related to the acceptance that full commitment might not be possible because of different organizational agendas, and the decision to focus on task accomplishment instead. However, the latter approach is perceived as difficult to implement by leaders (e.g. regional coordinators) because these leaders lack formal authority in inter-organizational work. Our further study also suggested that regional coordinators preferred not to act in a directive manner when working together with other organizations (Pucher et al., 2015a).

The current results suggest that strategies targeting the DISC factors can be used to enhance stakeholders' support in CSHP, which is an important precondition for the sustainability of the collaboration and the implementation of the HSA. However, several limitations should be considered, such as the specific context of our findings. The collaborative processes are the results of the particular emphasis on the DISC factors of change management and project management in the trajectory. It is therefore not surprising that change management was the most important predictor of stakeholders' support. It is conceivable that interventions based on alternative models and probably with different perspective on sustainable collaboration (such as development of stakeholders' capacity) could reveal other collaborative processes which also generate the desired outcomes. Further limitations relate to the small sample size in our study. For instance path analyses were conducted at the level of factors, which in turn are constituted of several indicators. Path analyses at these lower-level indicators (e.g. consensus, commitment, formalization) could provide more insights into the collaborative processes, and also into the distinct character of collaboration in CSHP compared to other domains in public health, or the general management literature and theory (Kegler and Swan, 2011a, b; Smith Ring and Van De Ven, 1994; Thomson and Perry, 2006; Wood and Gray, 1991; Vangen and Huxham, 2003). The study sample was too small to generate sufficient statistical power for these analyses, however. Furthermore, due to the small sample size, we were not able to study results per sector. An analysis comparing sectors could reveal that different sectors are sensitive to different strategies. Another limitation is the small number of collaborations studied (i.e. five), which did not allow for analyses at the level of partnerships. One might want that the relations as uncovered in this study at the level of individual stakeholders also hold at partnership level. Although this seems plausible, this in principle remains to be clarified empirically.

An additional limitation relates to the pretest-posttest design without a control group which makes our results vulnerable to maturation bias and history bias, limiting the possibility to draw causal inferences. Our study also suffered from drop-out. We minimized the detrimental effects of drop-out by applying specific analysis techniques (i.e. linear mixed regression models with random intercept) which enabled more reliable estimations and tests of effects compared to analyses based only on complete cases. However, we cannot fully exclude the effects of selective drop-out.

Finally, the collaborative agenda may have been affected by selection bias, as regional coordinators identified relevant stakeholders. It might be that the desire to achieve their own organizational goals (e.g. youth health, health promotion) guided their choice. Conducting an objective stakeholder analysis might be valuable in this respect.

To conclude, this study is one of the few which have used longitudinal, quantitative data to study collaborative processes, including the mediating role of stakeholders' support. Despite its limitations, it provides important insights for health professionals involved in establishing collaboration for CSHP and in implementing CSHP. Our findings suggest that 
strengthening stakeholders' support should be an important task for these health professionals. When the main aim is to establish sustainable collaboration, strategies should aim at effective change management and project management, as well as factors in the wider context (i.e. context, external factors) which can create important opportunities for collaboration. However, health professionals should be reminded that whereas negotiation may be a necessary strategy to get stakeholders' consensus and commitment to enhance stakeholders' support, it could be less effective in terms of getting things done, or at least this is what our study suggests. The utilization of directive management styles might be necessary, too. However, especially as regards the latter, further replication of the findings will be needed before final implications can be formulated for practice.

\section{References}

Barry, M.M., Battel-Kirk, B., Davison, H., Dempsey, C., Parish, R., Schipperen, M., Speller, V., Van Der Zanden, G. and Zilnyk, A. (2012), The CompHP Project Handbooks, International Union for Health Promotion and Education (IUHPE), Paris.

Boot, M.W.M., Van Assema, P., Hesdahl, B. and De Vries, N.K. (2010), "Professional assistance in implementing school health policies", Health Education, Vol. 110 No. 4, pp. 294-308.

Boot, N.M.W.M. and De Vries, N.K. (2012), "Implementation of school health promotion: consequences for professional assistance", Health Education, Vol. 112 No. 5, pp. 436-447.

Buijs, G.J. (2005), "Werkdocument. De Gezonde School Methode in Nederland (Work document. The Healthy School Approach in the Netherlands)", National Instituut voor Gezondheidsbevordering en Ziekte preventie (Netherlands Institute for Health Promotion and Disease Prevention), Woerden.

Butterfoss, F. and Kegler, M. (2002), "Toward a comprehensive understanding of community coalitions: moving from practice to theory", in DiClemente, R., Crosby, R. and Kegler, M. (Eds), Emerging Theories in Health Promotion Practice and Research, Jossey-Bass, San Francisco, CA, pp. 157-193.

Butterfoss, F., Goodman, R. and Wandersman, A. (1993), "Community coalitions for prevention and health promotion", Health Education Research, Vol. 8 No. 3, pp. 315-330.

Butterfoss, F.D. (2007), Coalitions and Partnerships in Community Health, Jossey-Bass, San Francisco, CA.

Butterfoss, F.D., Goodman, R.M. and Wandersman, A. (1996), "Community coalitions for prevention and health promotion: factors predicting satisfaction, participation and planning", Health Quarterly, Vol. 23 No. 1, pp. 65-79.

Clark, N., Doctor, L., Friedman, A., Lachance, L., Houle, C., Geng, X. and Grisso, J. (2006), “Community coalitions to control chronic disease: allies against asthma as a model and case study", Health Promotion Practice, Vol. 7 No. 2, pp. 13S-22S.

Cohen, J. (1988), Statistical Power Analysis for the Behavioral Sciences, 2nd ed., Lawrence Erlbaum Associates, New York, NY.

Cohen, J. (1992), “A power primer”, Psychological Bulletin, Vol. 112 No. 1, pp. 155-159.

Crowley, K., Yu, P. and Kaftarian, S. (2000), "Prevention actions and activities make a difference: a structural equation model of coalition building", Evaluation and Program Planning, Vol. 23 No. 3, pp. 381-388.

Cummings, T.G. and Worley, C.G. (2001), Organizational Development and Change, 7th ed., SouthernWestern College Publishing, Mason, OH.

Daft, R.L. and Noe, R.A. (2001), Organizational Behavior, Hartcourt Inc., Orlando, FL.

De Caluwé, L. and Vermaak, H. (2003), Learning to Change, Sage Publications, Thousand Oaks, CA.

Deschesnes, M., Drouin, N. and Couturier, Y. (2013), "Schools' absorptive capacity to innovate in health promotion”, Journal of Health Organization and Management, Vol. 27 No. 1, pp. 24-41.
Comprehensive school health promotion 
$\mathrm{HE}$ 117,1

Deschesnes, M., Couturier, Y., Laberge, S. and Campeau, L. (2010), "How divergent conceptions among health and education stakeholders influence the dissemination of healthy schools in Quebec", Health Promotion International, Vol. 25 No. 4, pp. 435-443.

Diamantopoulos, A. and Winklhofer, H.M. (2001), "Index construction with formative indicators: an alternative to scale development", Journal of Marketing Research, Vol. 38 No. 2, pp. 269-277.

Feinberg, M., Greenberg, M. and Osgood, D. (2004), "Readiness, functioning and perceived effectiveness in community prevention coalitions: a study of communities that care", American Journal of Community Psychology, Vols 3/4 No. 33, pp. 163-176.

Flaschberger, E., Gugglberger, L. and Dietscher, C. (2013), "Learning in networks: individual teacher learning versus organizational learning in a regional health-promoting schools network", Health Education Research, Vol. 28 No. 6, pp. 993-1003.

Florin, P., Mitchell, R., Stevenson, J. and Klein, I. (2000), "Predicting intermediate outcomes for prevention coalitions: a developmental perspective", Evaluation and Program Planning, Vol. 23 No. 3, pp. 341-346.

Gray, B. (1989), Collaborating: Finding Common Ground for Multiparty Problems, 1st ed., Jossey-Bass, San Francisco, CA.

Hirsch Ballin, E.M.H. (2008), "Wet Publike Gezondheid (Public Health Act)", available at: http://wetten. overheid.n1/BWBR0024705/geldigheidsdatum_14-04-2015 (accessed April 14, 2015).

Huxham, C. and Vangen, S. (1996), "Working together", International Journal of Public Sector Management, Vol. 9 No. 7, pp. 5-17.

Huxham, C. and Vangen, S. (2000), "Leadership in the shaping and implementation of collaboration agendas: how things happen in a (not quite) joined-up world", Academy of Management Journal, Vol. 43 No. 6, pp. 1159-1175.

IUHPE (2009), "Achieving health promoting schools: guidelines for promoting health in schools", available at: www.iuhpe.org/images/PUBLICATIONS/THEMATIC/HPS/HPSGuidelines_ENG. pdf (assessed January 15, 2015).

Jongh, D.de. and Bos, V. (2010), Handleiding gezonde school: basisonderwijs (Healthy School Guide: Primary School), RIVM Centrum Gezond Leven (National Institute for Public Health and the Environment-Centre of Healthy Living), Bilthoven.

Kegler, M.C. and Swan, D.W. (2011a), "Advancing coalition theory: the effect of coalition factors on community capacity mediated by member engagement", Health Education Research, Vol. 27 No. 4, pp. 572-584.

Kegler, M.C. and Swan, D.W. (2011b), “An initial attempt at operationalizing and testing the community coalition action theory", Health Education \& Behavior, Vol. 38 No. 3, pp. 261-270.

Lasker, R., Weiss, E. and Miller, R. (2001), "Partnership synergy: a practical framework for studying and strengthening the collaborative advantage", The Milbank Quarterly, Vol. 79 No. 2, pp. 179-205.

Leurs, M., Steenbakkers, M. and Jansen, M. (2006), "Het schoolSlag-praktijkboek: samen werken aan preventie op maat in het onderwijs (The schoolBeat manual: working together towards tailored prevention in education)", GGD Zuid Limburg, Maastricht.

Leurs, M., Jansen, M., Schaalma, H., Mur-Veeman, I. and De Vries, N. (2005a), "The tailored schoolbeat-approach: new concepts for health promotion in schools in the Netherlands", in Clift, S. and Jansen, B.B. (Eds), The Health Promoting School: International Advances in Theory, Evaluation and Practice, Danish University Press in Association with WHO, Copenhagen, pp. 87-106.

Leurs, M., Mur-Veeman, I., Van Der Sar, R., Schaalma, H. and De Vries, N. (2008), "Diagnosis of sustainable collaboration in health promotion - a case study", BMC Public Health, Vol. 8 No. 382, doi: 10.1186/1471-2458-8-382. 
Leurs, M., Schaalma, H., Jansen, M., Mur-Veeman, I., St Leger, L. and De Vries, N. (2005b), "Development of a collaborative model to improve school health promotion in the Netherlands", Health Promotion International, Vol. 20 No. 3, pp. 296-305.

Mcmorris, L.E., Gottlieb, N.H. and Sneden, G.G. (2005), "Developmental stages in public health partnerships: a practical perspective”, Health Promotion Practice, Vol. 6 No. 2, pp. 219-226.

Mackinnon, D.P., Lockwood, C.M., Hoffman, J.M., West, S.G. and Sheets, V. (2002), “A comparison of methods to test mediation and other intervening variable effects”, Psychological Methods, Vol. 7 No. 1, pp. 83-104.

Mur-Veeman, I. and Van Raak, A. (1994), "Inter-organizational networks on the Dutch home health care market”, The International Journal of Health Planning and Management, Vol. 9 No. 3, pp. 245-258.

Preacher, K.J. and Hayes, A.F. (2004), "SPSS and SAS procedures for estimating indirect effects in simple mediation models", Behavior Research Methods, Instruments, and Computers, Vol. 36 No. 4, pp. 717-731.

Pucher, K.K., Candel, M.J.J.M., Boot, N.M.W.M. and De Vries, N.K. (2015a), "Effectiveness of a systematic approach to promote intersectoral collaboration in comprehensive school health promotion: a multiple case study using quantitative and qualitative data”, BMC Health Education, Vol. 15 No. 613, pp. 1-14, doi: 10.1186/s12889-015-1911-2.

Pucher, K.K., Candel, M.J.J.M., Boot, N.M.W.M., Van Raak, A. and De Vries, N.K. (2015b), “A multiplecase study of intersectoral collaboration in the context of coordinated school health promotion using the DIagnosis of Sustainable Collaboration (DISC) Model”, Health Education, Vol. 115 Nos 3/4, pp. 301-321.

Roussos, S.T. and Fawcett, S.B. (2000), "A review of collaborative partnerships as strategy for improving community health”, Annual Review of Public Health, Vol. 21, pp. 369-402.

Shediac-Rizkallah, M.C. and Bone, L.R. (1998), "Planning for the sustainability of community-based health programs: conceptual frameworks and future directions for research, practice and policy”, Health Education Research, Vol. 13 No. 1, pp. 87-108.

Smith Ring, P. and Van De Ven, A.H. (1994), "Developmental processes of cooperative interorganizational relationships”, Academy of Management Review, Vol. 19 No. 1, pp. 901-118.

Snijders, T. and Bosker, R. (1999), Multilevel Analysis. An Introduction to Basic and Advanced Multilevel Modelling, Sage Publications, Thousand Oaks, London and New Delhi.

Sridharan, S. and Gillespie, D. (2004), "Sustaining problem-solving capacity in collaborative networks", Criminology \& Public Policy, Vol. 3 No. 2, pp. 221-250.

Stahl, T., Wismar, M., Ollila, E., Lahtinen, E. and Leppo, K. (2006), Health in All Policies. Prospects and Potentials, Ministry of Social Affairs and Health.

Steckler, A. and Goodman, R.M. (1989), "How to institutionalize health programs", American Journal of Health Promotion, Vol. 3 No. 1, pp. 34-43.

Stewart-Brown, S. (2006), "What is the evidence on school health promotion in improving health or preventing disease: and specifically, what is the effectiveness of the health promoting schools approach?”, WHO Regional Office for Europe, Copenhagen.

Teutsch, F., Gugglberger, L. and Dür, W. (2014), "School health promotion providers' roles in practice and theory: results from a case study", Health Policy, Vol. 119 No. 1, pp. 82-87, available at: www. healthpolicyjrnl.com/article/S0168-8510(14)00234-6/abstract (accessed September 4, 2014).

Thomson, A.M. and Perry, J.L. (2006), "Collaboration processes: inside the black box", Public Administration Review, Vol. 66 No. S1, pp. 20-32.

Comprehensive school health promotion

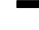


$\mathrm{HE}$

117,1

20

Van Raak, A., Mur-Veeman, I. and Paulus, A. (1999), "Understanding the feasibility of integrated care: a rival viewpoint on the influence of actions and the institutional context", The International Journal of Health Planning and Management, Vol. 14 No. 3, pp. 235-248.

Van Raak, A., Mur-Veeman, I., Hardy, B., Steenbergen, M. and Paulus, A. (2003), Integrated Care in Europe - Description and Comparison of Integrated Care in Six EU Countries, Elzevier Gezondheidszorg, Maarssen.

Vangen, S. and Huxham, C. (2003), "Enacting leadership for collaborative advantage: dilemmas of ideology and pragmatism in the activities of partnership managers", British Journal of Management, Vol. 14, pp. S61-S76.

Warner, M. and Gould, N. (2009), "Integrating health in all policies at the local level: using network governance to create "virtual reorganization by design'”, in Kickbusch, I. (Ed.), Policy Innovation for Health, Springer, pp. 125-163.

Wood, D.J. and Gray, B. (1991), "Toward a comprehensive theory of collaboration", The Journal of Applied Behavioral Science, Vol. 27 No. 2, pp. 139-162.

Yin, R.K. (1979), Changing Urban Bureaucracies: How New Practices Become Routinizezed, Lexington Books, Lexington, MA.

Zuckerman, H.S., Kaluzny, A.D. and Ricketts, T.C. (1995), "Alliances in health care: what we know, what we think we know, and what we should know", Health Care Management Review, Vol. 20 No. 1, pp. 54-64. 
Appendix

\begin{tabular}{lll}
\hline Factors & Subfactors & General description per construct \\
\hline External factors & Policy and regulations & The collaborative process is influenced by a number
\end{tabular}
of factors that are beyond the control or influence of the alliance itself

Clear, preferably intersectoral policies, laws and regulations providing challenging and sound goals for health promotion may enhance the collaborative process

Limiting factors may be diffuse borders between policy domains, contradictory policies of different public sectors and policies focusing on the transformation of public organizations into private enterprises

Attitudes of financing bodies

An encouraging and accommodating attitude of financing bodies and commitment to provide the necessary funding over a longer period to prevent a brain drain from starting during the initial developmental phase supports the collaborative process

Community notion

$\begin{array}{ll}\text { Context } & \text { (a) Existing alliances } \\ \text { (b) Characteristics of } \\ \text { organizations } \\ \text { (c) Research power } \\ \text { (d) Directly relevant } \\ \text { governmental policies }\end{array}$

Change management (a) Vision

(b) Innovation perspective

(c) Change strategies

(d) Network development

Project -

Who: actors

management the individual interest of each party and can additionally stimulate organizations to work together on comprehensive school health promotion. Incentives, policies and regulations can increase community notion for comprehensive school health promotion, as can parent, school staff and other collaborating parties who show social interest for comprehensive school health promotion

The collaborative process evolves in a context which can be influenced by the partners themselves When parties have had more positive experiences with each other in previous collaborative processes, need less energy for internal changes, have more research power and feel more supported by policies which they can influence as well, they are more open to sustainable collaborative process supporting intersectoral health promotion

The desired change requires management by one or a small group of leaders

In order to establish a successful collaboration, individual and collective leadership skills are necessary to guide the developmental process. Change management strategies should fit the chosen innovation perspective and be supportive of the subject of health promotion. The most relevant actors are included, and where these are missing, this will be accomplished by extending the network of the leaders of the collaborative process

During the development and initial implementation phase, the collaborative process is dealt with as a
What: tasks

How: structure
Comprehensive school health promotion project in a project management structure This includes deciding who are the actors in the

(continued)

Table AI.

General description of the DISC factors and related subfactors 
$\mathrm{HE}$

Support based on intersectoral collaboration
Perceptions
(a) Goals
(b) Importance
(c) Win-win
(d) Consensus
(e) Involvement

Intentions to
(a) Mutual trust
(b) Commitment
(c) Change

Actions

(a) Changes

(b) Reallocation of resources

(c) Formalization

From idea and project management to formalized regular work

project, what they need to do and how they operate (planning, procedures, evaluation, communication, etc.). This project management structure fades out when the subject of the collaborative process is integrated (or close to being integrated) in the regular work, and the alliance becomes self-supportive The stakeholders' support can be assessed at the perceptions, intentions and actions levels of the parties involved

Intersectoral collaboration evolves more smoothly when participating organizations share goals and interests, perceive positive outcomes supportive of their own goals, are able to reach consensus on the goal of the collaborative process and are of the opinion that the most relevant parties are involved in the collaborative process

Parties involved should start with the intention to trust each other (if not present, this needs to be worked on first), the intention to commit themselves to the collaborative process and its subject and the intention to introduce changes within their own organization, if needed, to promote the collaborative process

The collaborative process may induce a wide variety of actions, varying from the implementation of major innovations within one's own organization to the inclusion of relatively minor adaptations in regular procedures. The actions may involve a reallocation of resources as well. Whatever actions result from a collaborative process, it is important that these are formalized in order to enhance sustainability. The level of formalization needed depends mainly on the type of action itself

Sustainable collaboration

Table AI.

Source: Adapted from Leurs et al. (2008)

The collaborative process influences the development of the CSHP and supports the move toward sustainability (goal). Under the continuous influence of the collaborative process, an idea is elaborated and develops into regular work routine by being formalized. During this process the subject of the collaborative process evolves: it "changes color" under the influence of the collaborative process itself 


\begin{tabular}{|c|c|c|c|c|c|c|c|}
\hline & & Multi-1 & analysis & & $\begin{array}{l}\text { Effect size } \\
\text { Cohen's } d /\end{array}$ & & school health \\
\hline & $b$ & $\mathrm{SE}(b)$ & $F$ & $p$-value & Cohen's $f^{2}$ & $\mathrm{ICC}$ & promotion \\
\hline Sustainable collaboration & & & & & & & \\
\hline Intervention & 0.291 & 0.084 & 11.973 & $0.001 * *$ & 0.58 & 0.201 & \\
\hline Stakeholders' support & 0.294 & 0.092 & 9.399 & $0.003^{* *}$ & 0.08 & & 23 \\
\hline Change management & 0.019 & 0.079 & 0.057 & 0.812 & & & \\
\hline Project management & 0.029 & 0.047 & 0.369 & 0.545 & & & \\
\hline Context & 0.069 & 0.064 & 1.157 & 0.284 & & & \\
\hline External factors & -0.015 & 0.054 & 0.078 & 0.781 & & & \\
\hline Execution of HSA activitie & & & & & & & \\
\hline Intervention & -0.027 & 0.089 & 0.094 & 0.759 & & 0.000 & \\
\hline Stakeholders' support & 0.338 & 0.096 & 12.446 & $0.001 * *$ & 0.10 & & \\
\hline Change management & 0.150 & 0.079 & 3.632 & $0.059 * * * *$ & 0.03 & & \\
\hline Project management & -0.106 & 0.048 & 4.926 & $0.028^{*}$ & 0.04 & & \\
\hline Context & -0.008 & 0.062 & 0.018 & 0.893 & & & \\
\hline External factors & 0.022 & 0.057 & 0.143 & 0.706 & & & Table AII. \\
\hline Stakeholders' support & & & & & & 0.079 & \\
\hline Intervention & 0.129 & 0.067 & 3.767 & $0.058 * * * *$ & 0.28 & & ollaboration, \\
\hline Change management & 0.300 & 0.061 & 24.265 & $0.000 * *$ & 0.18 & & on of the HSA \\
\hline Project management & 0.151 & 0.038 & 15.469 & $0.000 * *$ & 0.13 & & orative sunport \\
\hline Context & 0.151 & 0.052 & 8.392 & $0.003^{* *}$ & 0.08 & & based on difference \\
\hline External factors & 0.101 & 0.045 & 5.105 & $0.026^{*}$ & 0.02 & & scores between pre \\
\hline Notes: ${ }^{*} p<0.05 ; * * p<0$ & $1 ; * * * p<0$ & $1 ; * * * * p$ & & & & & and posttest \\
\hline & & Mult & el analysi & & Effect size & & \\
\hline & $b$ & $\mathrm{SE}(b)$ & $F$ & $p$-value & Cohen's $d$ & ICC & \\
\hline DISC factors & & & & & & & \\
\hline Stakeholders' support & 0.313 & 0.081 & 14.868 & $0.000 * *$ & 0.43 & 0.181 & \\
\hline Change management & 0.327 & 0.125 & 6.871 & $0.010^{* *}$ & 0.38 & 0.253 & \\
\hline Project management & 0.485 & 0.173 & 7.849 & $0.006^{* *}$ & 0.41 & 0.525 & Table AIII. \\
\hline Context & 0.019 & 0.120 & 0.026 & 0.371 & & 0.326 & Influence of the DISC- \\
\hline External factors & 0.330 & 0.143 & 5.604 & $0.019^{*}$ & 0.37 & 0.045 & based trajectory on \\
\hline Outcome measures & & & & & & & the DISC factors, \\
\hline Sustainable collaboration & 0.363 & 0.086 & 17.733 & $0.000^{* * * *}$ & 0.65 & 0.496 & collahoration and \\
\hline Executed HSA activities & 0.175 & 0.092 & 3.614 & $0.060 * * * *$ & 0.35 & 0.033 & execution of the HSA \\
\hline Notes: $* p<0.05 ; * * p<0$ & $1 ; * * * p<0$ & $; * * * * p$ & & & & & activities \\
\hline
\end{tabular}

\section{Corresponding author}

Katharina K. Pucher can be contacted at: Katharina.Pucher@uni-wh.de; k.pucher@dshs-koeln.de

For instructions on how to order reprints of this article, please visit our website: 